\title{
A Corpus-Based Comparative Study of Chinese EFL Learners' Use of Temporal Metaphor in English
}

\author{
Yi Guo $^{1}$ \\ ${ }^{1}$ Post-Doctoral Research Center, Shanghai International Studies University, Shanghai, China \\ Correspondence: Yi Guo, Post-Doctoral Research Center, Shanghai International Studies University, Shanghai, \\ China. E-mail: jassie_kwok@hotmail.com
}

Received: May 5, $2019 \quad$ Accepted: May 30, $2019 \quad$ Online Published: June 12, 2019
$\begin{array}{ll}\text { doi:10.5539/ijel.v9n4p51 } & \text { URL: https://doi.org/10.5539/ijel.v9n4p51 }\end{array}$

\begin{abstract}
This paper adopted a corpus-based approach to compare the uses of the conceptual metaphor "TIME IS MONEY" between Chinese non-English major college students and native speakers of English. The results revealed no direct correspondence between frequency of metaphorical use and proficiency level of English. While EFL learners differed with native speakers in terms of the diversity of metaphorical uses, the patterns of high-frequency uses were similar between the two groups. Chinese EFL learners were prone to produce unidiomatic metaphorical expressions that literally make sense. These expressions could be the mixed results of negative L1 transfer and insufficient L2 proficiency, especially the lack of adequate semantic knowledge in English. To language learners, conceptual metaphor in L2 cannot be randomly created, but has to be acquired with the help of the cultural knowledge embedded in the metaphorical expressions.
\end{abstract}

Keywords: conceptual metaphor, TIME IS MONEY, corpus-based, comparative study, EFL learners

\section{Introduction}

The study of metaphor dates back to more than two thousand years ago. Since the ancient Greek time, there has been the convention of seeing metaphor as a typical rhetorical device, a figure of speech in which a word or phrase is used to describe a person or object to which it is not literally applicable. However, in the recent decades, groundbreaking changes have taken place within the field of linguistic studies, leading to the genesis of Cognitive Linguistics in the 1980s. Since the monumental publication of the book Metaphor We Live By (Lakoff \& Johnson, 1980), the study of metaphor has gradually been detached from its traditional literary base and reoriented towards the direction of cognitive science. Metaphor, with a great emphasis on its influence upon human cognitive system, has been redefined as not simply a means of figurative language use, but more importantly, a cognitive mechanism that is deeply entrenched in human thought and helps reflect the way we conceptualize the world.

Given the acknowledged significance of metaphor as a fundamental cognitive ability of human beings, L2 learners' use and processing of metaphors could be even more complicated in view of the interplay of at least two languages. When introducing the concept of metaphor to college students of English linguistics, Ding and Hauck (2004) took the metaphor "TIME IS MONEY" as a commonly used example. It was claimed that "we should avoid collocations that are not in keeping with the 'TIME IS MONEY' metaphor". For instance, EFL learners should refrain from saying "she distributes her time wisely" or "I should tightly grasp my time" (p. 167). Despite the prescriptive warnings, the reasons why EFL learners are inclined to produce these expressions and why these metaphorical expressions are considered illegitimate in L1 use of English are the important issues that remain unknown. In search of the keys to these unsettled questions, the current research adopted a corpus-based approach to investigate Chinese EFL learners' and native English speakers' uses of the typical conceptual metaphor "TIME IS MONEY". By revealing the patterns of unidiomatic metaphorical uses produced by Chinese EFL learners, the study could provide a number of findings for research on metaphorical competence from an L2 perspective.

\section{Literature Review}

Among the huge variety of related studies on metaphor, there has been some research that specifically concentrated on analyzing different themes of metaphorical expressions, such as discussing the origins and 
metaphorical uses of language about human emotions (Kövecses, 2000). More researchers, refusing to be restricted to the study of conceptual metaphor within a certain language, have chosen miscellaneous metaphorical themes and adopted a comparative paradigm to analyze the metaphorical expressions among different languages. Concerning the theme-specific and cross-linguistic studies, some researchers have compared English and Chinese metaphorical expressions from a cognitive linguistic perspective. For instance, Qin and Huang (2003) probed into the conceptual metaphors of "darkness" in English and Chinese and found that most of the mappings are shared by the two languages. In a series of studies on the conceptual metaphors of human emotions, Qu (2008a, 2008b) focused on "happiness" and "anger" metaphors and revealed the similarities and differences of the related expressions in Chinese and English. Drawing on the cognitive linguistic theory of embodiment, Chen (2008) presented the similarities and differences of emotional metaphors about "fear" between Chinese and English. Moreover, Lei and Qin (2013) investigated the metaphors concerning the concept of "hot" from the embodied cognitive perspective. Recent studies have extended the scope of analysis and involved a wider range of metaphorical themes, including, for example, the "animal" metaphors as embedded in plant names (Chen, 2015) and "moral" metaphors as reflected from the corpus-based studies on the uses of concepts concerning "dirt" and "cleanliness" in English and Chinese (Luo \& Zhang, 2016).

In addition to the above comparative studies that covered a variety of metaphorical themes, some other researchers have paid special attention to the conceptual metaphors related to time and space and compared the similarities and differences of the metaphorical uses in English and Chinese. For example, Zhou (2000) proposed 11 structural dimensions of the "time" concept and carried out a content analysis and a factor analysis to explore the way of conceptually structuring the metaphorical representation of time. The results indicated that English and Chinese metaphorical uses of time share some similar structural dimensions, and are both intensely and systematically structured in a conceptual manner. From the perspectives of cognitive science, semantics and culture, Wang (2006) suggested that the complexity of duality in temporal metaphor is better captured within the framework of Talmy's Active-determinative Principle. In a corpus-based study of spatial metaphor (Zhou \& Zhang, 2003), focus was placed on the metaphorical uses of "high" and "low". Based on the data extracted from the British National Corpus, the study categorized the projection of "high" and "low" onto five target domains, including quantity, time, status, state and sensation. Alternatively, Cheng (2017) applied the theory of prototype-model to compare the markedness of English and Chinese spatial metaphorical twin-word orders. It was revealed that the similar cognitive foundations and the cultural dissimilarities respectively served to account for the similarities and differences between the metaphors of the two languages.

Regarding the research on English and Chinese temporal-spatial conceptual metaphors, there are several studies that selected specific metaphors under the themes of time and space, and compared the similarities and differences of their respective uses in the two languages. For example, Zhang and Ding (2003) focused on the conceptual metaphor "TIME PASSING IS MOTION" and conducted a comparative study between English and Chinese temporal metaphors at a lexical level. It was found that time words in English and Chinese are respectively transparent in morphemic and semantic motivations. While time has the tendency of being personified in English collocations, it is more likely to be materialized in specific manners in Chinese. In a similar vein, Sun and Chen (2009) testified the universality of the conceptual metaphor "TIME IS SPACE" between English and Chinese. In the process of describing the cognitive and distributional patterns of the metaphorical uses, the study revealed some similarities of the underlying experiential philosophical foundations of the two languages.

Taking the abovementioned research on conceptual metaphors into consideration, it has been observed that the majority of the previous studies have taken a cross-linguistic approach to compare English and Chinese metaphorical expressions with regard to certain metaphorical themes. In contrast, research on L2 learners' use of metaphor under a comparative paradigm still remains scarce in literature. So far, insufficient attention has been paid to Chinese EFL learners' use of conceptual metaphors in various learning situations such as speaking and writing, as well as the comparisons of metaphorical uses between Chinese EFL learners and native speakers of English. Since metaphor is generally considered as the basis of human cognition and experience, what are the main factors that exert influence on language learners' use of metaphors in L2? What are the sources that might lead to unidiomatic expressions as reflected from L2 learners' interlanguage? For L2 learners, is the use of metaphor a cognitive mechanism involving the operations of mapping from source to target domains? Or, is the correct and idiomatic use of metaphor more likely to be nurtured by means of observing and imitating in the process of learning? To answer these questions concerning the use of theme-specific metaphors in L1 and L2, a small-scaled corpus-based study was conducted to investigate Chinese EFL learners' use of temporal metaphors, with a special highlight on the metaphor "TIME IS MONEY" and L2 learners' use of this metaphor in 
composition writing.

\section{Methods}

\subsection{Corpora Information}

In the current study, the major search tool used in the corpus analysis was the WConcord 3.0, which allows for loading multiple plain text files (.txt) and creating concordances on the basis of simple or complex search patterns. Two corpora were selected for the comparative study. One was Gui and Yang's (2003) Chinese Learner English Corpus (henceforward CLEC), and the other one was the Brown Corpus (henceforward BROWN), which targets language data collected from native speakers of American English. In the CLEC, we further selected the sub-corpora of composition writing from the band 4 and band 6 of College English Test (CET). The data contributors of the former sub-corpus (CET 4) represented college-level non-English major students of low English proficiency (henceforward NML), and the latter (CET 6) represented non-English major students of higher English proficiency (henceforward NMH). Hence, we aimed at comparing and contrasting the uses of metaphors by a total of three groups of language users, i.e., native speakers of English, Chinese EFL learners of low and of higher English proficiency.

\subsection{Corpus Data Extraction}

The WConcord 3.0 was used to extract lists of co-occurrences that contained the word "time" in the native speaker and the learner corpora. The numbers of concordance lines were 720 for NML, 1143 for NMH and 1696 for BROWN. Of all the extracted data, the concordance lines containing non-metaphorical uses of "time" were deleted. These included the prepositional phrases of time (e.g., at/in/for/after...time), noun phrases (e.g., first/second/most/this/that/all/some/any/every time, part-time job, span of time), and collocations such as from time to time, once upon a time, in due time, keep up with the time, ahead of time and it is (high) time. After the deletion process, the numbers of uses left in the three corpora were 252 (NML), 419 (NMH) and 200 (BROWN).

\subsection{Results and Analysis}

With regard to the frequency of use, native speakers of English had been supposed to use metaphors more actively than L2 learners. However, the results of data analysis failed to provide clear support for this hypothesis. According to the comparison of uses among the three groups (see Table 1), the metaphorical uses of "TIME IS MONEY" only accounted for $11.8 \%$ of all the uses of the given search word "time" in the BROWN group. In contrast, the percentages of metaphorical uses in the NML and the NMH groups were $35 \%$ and $36.7 \%$ respectively, which were not significantly different, and both much higher than the statistics of the native speaker group. Hence, the above comparison of results violated the assumption that the higher the language proficiency is, the more metaphorical uses of this language should be detected.

Table 1. Frequencies of "time" and "TIME IS MONEY" in the three corpora

\begin{tabular}{llll}
\hline Corpus Name & Frequency of Uses in Total & Frequency of Metaphorical Uses & Percentage of Metaphorical Uses \\
\hline NML & 720 & 252 & $35 \%$ \\
NMH & 1143 & 419 & $36.7 \%$ \\
BROWN & 1696 & 200 & $11.8 \%$ \\
\hline
\end{tabular}

In spite of the unexpected statistics on the surface, a closer examination of the corpora data revealed that some factors might have created noise to affect the general results. It seemed that merely comparing the frequencies of occurrences in the corpora data might not be enough to reflect the uses of metaphors by the three groups of language users. In particular, the composition writing data extracted from the CLEC were composed of the testees' writing task performances in the CET 4 and CET 6. The topic of the writing task per se seemed to exert a significant influence on the results of the analysis concerning the uses of temporal metaphors. For instance, it was found out that the topic and task description of composition writing (CET 4) in 1995 was "Nowadays it has become fashionable for college students to take a part-time job in their spare time. Discuss the advantages and disadvantages of this trend". The word "time" occurred twice in the topic already, i.e., part-time and spare time. Besides, the single collocation of spare time in the writing texts greatly increased the metaphorical uses of "TIME IS MONEY". Thus, it seemed that in the current comparative study, frequency of use could not be defined as an effective predictor of language users' metaphorical competence. More comparisons taking, for instance, the most highly frequent metaphorical uses into account might shed new light on the issue in discussion. 
Table 2 presents the statistics of the top five high-frequency metaphorical usages in each of the three corpora. As can be seen from the table, the summed percentages of the top five most frequently-occurred uses of "TIME IS MONEY" decreased from the NML to the BROWN group. A comparison of the detailed uses revealed that collocations such as spend time/have time/waste time were commonly used and appeared in the top five lists of all the three corpora. The patterns of these particularly high-frequency uses did not demonstrate much difference among the three groups. However, it was noticed that the token frequency of spare time was extraordinarily high in the NML group. As it has been mentioned before, this might be a corollary of the composition writing topic of the CET 4. Given the request of analyzing the pros and cons of taking a part-time job in spare time, learners of the NML group could not refrain from using spare time in writing. Nevertheless, it has to be pointed out here that although spare time is a legitimate use of "TIME IS MONEY" in English, it does not necessarily mean that the learners in the NML group were actively using the temporal metaphor when they wrote down spare time in the writing test. Especially in view of the disturbance generated by the topic of writing in CET 4, we need to take other factors, such as the diversity of uses, into further consideration.

Table 2. Top five high-frequency metaphorical usages in the three corpora

\begin{tabular}{|c|c|c|c|}
\hline Rank & $\begin{array}{l}\text { Metaphorical Use, Frequency and } \\
\text { Percentage in NML }\end{array}$ & $\begin{array}{l}\text { Metaphorical Use, Frequency and } \\
\text { Percentage in NMH }\end{array}$ & $\begin{array}{l}\text { Metaphorical Use, Frequency and } \\
\text { Percentage in BROWN }\end{array}$ \\
\hline 1 & spare time $57(22.6 \%)$ & waste time $84(20.0 \%)$ & spend time $34(17 \%)$ \\
\hline 2 & spend time $46(18.3 \%)$ & spend time $81(19.3 \%)$ & have time $34(17 \%)$ \\
\hline 3 & have time $37(14.7 \%)$ & have time $62(14.8 \%)$ & take time $30(15 \%)$ \\
\hline 4 & waste time $26(10.3 \%)$ & need time $32(7.6 \%)$ & waste time $16(8 \%)$ \\
\hline 5 & use (make use of) time $19(7.5 \%)$ & save time $29(6.9 \%)$ & give time $12(6 \%)$ \\
\hline Total & $185(73.4 \%)$ & $288(68.7 \%)$ & $126(63 \%)$ \\
\hline
\end{tabular}

Table 3 is a further comparison of the three groups' metaphorical uses, which excluded the above top five high-frequency uses for the purpose of demonstrating the diversity of uses among different language learners. Judging from the remaining concordance lines and the variety of uses, it could be calculated that the diversity of metaphorical uses presented by the native speaker group was richer than both of the L2 groups. However, within the L2 category, the two groups' statistics did not provide evidence for a link between proficiency level and diversity of uses. In fact, there were more miscellaneous uses of "TIME IS MONEY" in the NML group, such as "one inch of time is more precious than one inch of gold", which was clearly a literal translation from a similar Chinese proverb. Hence, it seemed that whereas the diversity of use is an effective predictor to distinguish between native and nonnative speakers concerning their different patterns of metaphorical uses, it is not equally predictive among different levels of nonnative speakers. This is because for nonnative speakers of English, diversity does not guarantee idiomaticity. A portion of the detected metaphorical uses could have been originated from negative L1 transfer, and would be gradually kept in control with the improvement of L2 proficiency.

Table 3. Diversity of metaphorical uses in the three corpora

\begin{tabular}{llll}
\hline Corpus Name & Remaining Concordance & $\begin{array}{l}\text { Types of Metaphorical } \\
\text { Uses }\end{array}$ & $\begin{array}{l}\text { Diversity of Metaphorical Uses } \\
\text { (Per 100 Lines) }\end{array}$ \\
\hline NML & Lines & 23 & 34.33 \\
NMH & 67 & 32 & 24.43 \\
BROWN & 131 & 31 & 41.89 \\
\hline
\end{tabular}

\section{Discussion}

\subsection{Major Sources Leading to the Unidiomatic Metaphorical Uses in L2}

It has already been mentioned in the introduction part that Chinese EFL learners are prone to produce unidiomatic uses, such as "grasp the time", when they are conveying the meaning of "TIME IS MONEY" in expressions of English. As expected, these unidiomatic sayings were also found in both the NML and the NMH groups. For instance, in the NML group, there was a variety of uses such as "we should plan our time", "he has to pay the time", "I must grasp the time" and "one inch of time is more precious than one inch of gold". In the NMH group, similar unidiomatic collocations such as "plan time", "take advantage of time" and "capitalize on time" were also detected. Given the fact that none of these uses were found in the Brown Corpus, it is worthwhile to further query why L2 learners produced such a great amount of uses that appear to reflect the 
metaphor "TIME IS MONEY" but are not shared by native English speakers. Two clusters of factors could be discussed for a possible explanation.

On the one hand, EFL learners' production of unidiomatic metaphorical expressions is directly associated with the negative influence of L1 transfer. Chinese college-level EFL learners, with approximately two decades of immersion in L1 language background, have gradually acquired the cognitive mechanisms that are engaged in metaphorical language use, and have been familiar with the conventional expressions of different metaphors in Chinese. These conventional uses of conceptual metaphors in L1 inevitably exert influence when L2 learning takes place, leading to the English versions of Chinese conventional sayings such as "one inch of time is more precious than one inch of gold". Interestingly, due to the same cultural background, Chinese EFL learners seem to share a sort of tacit understanding when they come across or write down these unidiomatic expressions in the learning process (Shen, 2000). Following this logic, L2 learners of relatively low language proficiency may even be unaware of the cross-linguistic differences in metaphorical expressions and feel confident when they are thinking in L1 and writing in L2.

In addition to the direct transfer of L1 metaphor that is not shared in L2, the case for conceptual metaphors that are shared in L1 and L2, such as the metaphor "TIME IS MONEY" as we have discussed in some length, could be no less problematic. Unequivocally, "TIME IS MONEY" is shared in both Chinese and English. However, it seems that learners of lower L2 proficiency usually cannot fully comprehend the interaction as well as the mutual constraint between the universality of conceptual metaphor and the idiomaticity of different linguistic conventions. Although "TIME IS MONEY" is a relatively universal metaphor at the conceptual level, its realization into expressions at the linguistic level is affected by the various conventions of different languages. This helps explain why collocations such as "plan time", "wisely distribute time" and "tightly grasp time" are categorized as malformed uses in English contexts, even if they make perfect sense when translated literally into Chinese.

On the other hand, incomplete L2 lexical knowledge is also held accountable for the unidiomatic uses of metaphor by EFL learners. For instance, an unidiomatic use of "TIME IS MONEY", i.e., "He has to pay the time and energy to finish the job", was detected in the NML group. The student who produced the expression of "pay the time and energy" had extended the semantic field of the verb pay by applying it to circumstances where it normally does not occur. According to the Oxford Advanced Learner's English-Chinese Dictionary (fourth edition), the usages of pay as a verb could be summarized as follows:

1) (a) give (sb) money (for goods, services, etc): Are you paying in cash or by cheque?

(b) give (what is owed); hand over the amount of sth: pay a bill, debt, fine, subscription, taxes, rates, rent, etc.

2) (a) (of a business, etc) be profitable: The shop closed because it didn't pay.

(b) be advantageous or profitable to (sb): It would pay (you) to use an accountant.

It seemed that the student who came up with "pay the time and energy" was not familiar with the contexts in which pay is usually used. Irrespective of the usage conventions of L2 vocabulary, what was memorized in the learning process was simply the decontextualized meaning of the verb. In this sense, the results of the current analysis points to the problem of L2 vocabulary learning from the perspective of conceptual metaphor. The misuses of pay have revealed EFL learners' lack of adequate semantic knowledge, which includes not only the so-called "meaning" of words, but also the equally important information concerning the contexts and collocational conventions formulated by the community of native English speakers (Kövecses, 2015).

\subsection{Solutions to Unidiomaticity in L2 Use of Conceptual Metaphor}

After clarifying the major sources that could lead to L2 production of unidiomatic expressions, it is necessary to probe further into the nature of L2 use of metaphor and the solutions as to how EFL learners can avoid unidiomaticity and produce relatively native-like metaphorical expressions in English. According to Lakoff and Johnson (1980), conceptual metaphors bring into correspondence two domains of knowledge. One is typically a well-delineated familiar physical domain (source domain) and the other a less well-delineated, less familiar, abstract domain (target domain). Despite the universality of metaphor at the conceptual level, the cognitive mode embedded in metaphor is deeply rooted in centuries of cultural history of a given language. Yet, owing to the long-term immersion in the cultural community, native English speakers generally have no difficulty gradually acquiring the linguistic conventions that constrain the random realizations of metaphorical thoughts in mind. Since most EFL learners have no access to the language environment granted to native speakers of English, is it tenable to deduce that the mechanism of cross-domain mapping in conceptual metaphor is equally applicable to L2 learning contexts? According to the results of data analysis in the current corpus-based study, the chance for 
the same mechanism to work in L2 appears to be slim.

For language learners, we have no reason to believe that the metaphorical competence, demonstrated via a language other than their mother tongues, can be automatically fine-tuned without accumulating adequate knowledge of the target language. New metaphor is not frequently created in everyday language use. Native speakers of English rely on a huge complex of social and cultural background knowledge to decipher and produce acceptable metaphorical uses. For L2 learners, merely comprehending these uses in a correct way has been difficult enough. The production of legitimate metaphorical uses in L2 writing is inevitably affected by implicit or explicit L1 transfer. Even if learners succeed in producing acceptable metaphorical uses, such as spend/waste/have time concerning "TIME IS MONEY", these expressions could hardly be categorized as active uses of the metaphor, but are more likely to be attributed to the cross-linguistic similarity reflected from this temporal metaphor in English and Chinese. Hence, for L2 learners, metaphorical use in a second language starts from comprehension rather than production, and is nurtured by observing and imitating in the process of learning. Instead of depending solely on the cognitive mechanism of cross-domain mapping, learners need to put extra effort into getting themselves familiarized with the metaphorical usages in the form of L2. Without a consideration of the rules and linguistic conventions, L2 metaphorical production has little regularity to resort to.

\section{Conclusion}

This paper has presented a corpus-based comparative study of Chinese EFL learners' and native English speakers' uses of the conceptual metaphor "TIME IS MONEY". There are three major findings. First, there seemed to be no correlation between frequency of metaphorical use and level of language proficiency. Although L2 learners differed from native English speakers as to the diversity of metaphorical expressions, the patterns of high-frequency uses were not significantly different. Second, L2 learners were prone to produce metaphorical uses that are unidiomatic but literally make sense. These uses might be the mixed results of negative L1 transfer and insufficient L2 lexical knowledge. Third, for L2 learners, the use of conceptual metaphor was not randomly created, but had to take into account the background knowledge of the target cultural community. The current study points to the new challenges for language pedagogy. Not only should linguistic researchers and ESL teachers try to apply the research findings to the classroom instruction of the cognitive structure of metaphor, it is also necessary for them to highlight the importance of paying attention to the underlying cultural connotations of metaphor in the target language. Given the role of metaphor as a fundamental mechanism that shapes the way we think and speak, our effort to compare the uses of the temporal metaphor "TIME IS MONEY" between Chinese and English could facilitate L2 learning of English practically, and help expand our understanding of figurative language studies in general.

\section{Acknowledgments}

This study has been partially supported by the project (2018SH0023B). "A cognitive linguistic approach to L2 processing of English idiom variation”, funded by Shanghai Foreign Language Education Press, P. R. China.

\section{References}

Chen, H. (2015). A contrastive study of animal metaphors in English and Chinese plant names. Journal of Xi'an International Studies University, 23(4), 1-5. https://doi.org/10.3969/j.issn.1673-9876.2015.04.001

Chen, J. (2008). A contrastive study of emotional metaphors about fear between English and Chinese. Journal of $\begin{array}{llll}\text { Sichuan International } & \text { Studies } & \text { University, } & \text { 24(1), }\end{array}$ https://doi.org/10.3969/j.issn.1674-6414.2008.01.014

Cheng, X. (2017). A contrastive analysis of the markedness of E-C spatial metaphorical twin word orders from the perspective of prototype-model theory. Foreign Language Research, 1, 49-53.

Ding, Y., \& Hauck, M. (2004). Linguistics for English learners. Shanghai: Shanghai Foreign Language Education Press.

Gui, S., \& Yang, H. (2003). Chinese learner English corpus. Shanghai: Shanghai Foreign Language Education Press.

Kövecses, Z. (2000). Metaphor and emotion: Language, culture, and body in human feeling. Cambridge and New York: Cambridge University Press.

Kövecses, Z. (2015). Where metaphors come from: Reconsidering context in metaphor. Oxford and New York: Oxford University Press. https://doi.org/10.1093/acprof:oso/9780190224868.001.0001

Lakoff, G., \& Johnson, M. (1980). Metaphors we live by. Chicago, IL: University of Chicago Press. 
Lei, D., \& Qin, X. (2013). Conceptual metaphors of hot from the embodied cognitive perspective: A comparative study between English and Chinese. Contemporary Foreign Languages Studies, 3, 24-28.

Luo, Y., \& Zhang, H. (2016). A corpus-based comparative study of the moral metaphors between English and Chinese. Foreign Languages Research, 6, 18-24. https://doi.org/10.13978/j.cnki.wyyj.2016.06.004

Qin, X., \& Huang, X. (2008). The conceptual metaphors of darkness: A corpus-based comparative study between English and Chinese. Journal of Xi'an International Studies University, 16(4), 9-13. https://doi.org/10.3969/j.issn.1673-9876.2008.04.003

Qu, Z. (2008a). Differences and similarities in metaphorical cognition of the emotion of anger between Chinese and English. Journal of Guangdong University of Foreign Studies, 19(6), 48-51. https://doi.org/10.3969/j.issn.1672-0962.2008.06.011

Qu, Z. (2008b). Differences and similarities in cognition of conceptual metaphors of emotion of happiness between Chinese and English. Journal of Xi'an International Studies University, 16(4), 14-17. https://doi.org/10.3969/j.issn.1673-9876.2008.04.004

Shen, L. (2000). The impact of folk metaphorical concepts on L2 metaphor acquisition. Fudan Journal (Social Sciences), 5, 105-109.

Sun, Y., \& Chen, L. (2009). A brief illustration of experiential philosophy in the domain of cross-language research of time-space conceptual metaphors. Journal of Beijing International Studies University, 6, 43-48.

Wang, S. (2006). The duality of metaphor: A case study of time metaphor. Foreign Languages and Their Teaching, 2, 58-60. https://doi.org/10.3969/j.issn.1004-6038.2006.02.016

Zhang, J., \& Ding, Z. (2003). A comparative study of temporal metaphor in English and Chinese. Foreign Languages and Their Teaching, 9, 31-34. https://doi.org/10.3969/j.issn.1004-6038.2003.09.010

Zhou, J., \& Zhang, J. (2003). A corpus-based study of spatial metaphor. Journal of PLA University of Foreign Languages, 26(5), 27-31. https://doi.org/10.3969/j.issn.1002-722X.2003.05.006

Zhou, R. (2000). A cross-cultural study of the metaphorical representation of time. Modern Foreign Languages, 23(1), 58-66. https://doi.org/10.3969/j.issn.1671-6981.2000.02.003

\section{Copyrights}

Copyright for this article is retained by the author, with first publication rights granted to the journal.

This is an open-access article distributed under the terms and conditions of the Creative Commons Attribution license (http://creativecommons.org/licenses/by/4.0/). 